\title{
Social Demands in Ubiquitous Computing: Contexts for Tomorrow's Learning
}

\author{
Mareen Przybylla $^{1}$ and Ralf Romeike ${ }^{2}$ \\ ${ }^{1}$ University of Potsdam, Germany \\ ${ }^{2}$ Friedrich-Alexander-Universität Erlangen-Nürnberg, Germany
}

\begin{abstract}
We live in times of digital change, which manifests in the increasing pervasiveness of embedded and cyber-physical systems in our society. This change also needs to be reflected in education, as new knowledge and competencies become necessary to deal with everyday life challenges, for instance when estimating consequences of capturing, transmitting and evaluating sensor data in many devices and acting accordingly and responsibly. This article examines requirements that the digital society places on CS education. In our analysis, we identified numerous contexts, activities and knowledge areas relevant for students to cope with challenges of the digital world. Combined with content knowledge relevant in this domain, suitable phenomena and thus anchor points for teaching can be generated and, on this basis, specific learning scenarios can be developed that also consider general educative aims imposed by our society.
\end{abstract}

Keywords: Computer Science, Education, Embedded Systems, Ubiquitous Computing, Social Demands

\section{Introduction and Motivation}

Less and less technical developments of today contain classic computers with display, keyboard and mouse. We are predominantly surrounded by mobile devices and reactive systems that capture context variables with the aid of sensors and affect the physical world with actuators. Today, more than $98 \%$ of all microprocessors are integrated in technical devices such as pace makers, navigation systems or household devices [3]. We live in the digital world-a place where "information is available almost anywhere at almost any time, computer power is ubiquitous, communication of vast amounts of information is almost instantaneous" [10]. Thus, society puts demands on CS education: dealing with embedded systems requires new knowledge and competencies that cannot be acquired in traditional teaching. To allow future generations to participate in social discourse, to understand media coverage and to make informed decisions, it is essential to address the relevant aspects in the classroom. However, it is unclear what those demands and aspects are, especially with regard to ubiquitous computing. Thus, in this article we give an overview of relevant technical aspects in this field, analyze interview transcripts and documents that reflect the perspectives of different stakeholders in this domain to extract the social demands on computer science in school in terms of ubiquitous computing and embedded and 
cyber-physical systems. We discuss possible implications for the selection of appropriate content and contexts for teaching.

\section{Phenomena of the Digital World: Ubiquitous Computing and Internet of Things}

In the last decades computing systems have evolved according to the vision of ubiquitous computing pioneer Mark Weiser, who already predicted pervasive, efficient and invisible computers at the beginning of the 1990s [19]. Ubiquitous Computing nowadays is commonplace thanks to appropriate technologies. In the Internet of Things (IoT), "things" that contain embedded systems (ES) or cyberphysical systems (CPS), are networked with various services on the Internet. The IoT offers new possibilities for the generation of information by converging data of many things. The physical world merges with the virtual: integrating Internet services allows real-time analyses that are used to influence the real world. As a result of the constantly increasing diversity of information available on the Internet and things that are networked with people and processes, the IoT is evolving to eventually become the Internet of Everything (IoE) [4, p. 72].

ES combine hard- and software components, are embedded into a technical context and fulfil predefined tasks. They usually control, regulate or monitor a system continuously. For this purpose, in addition to possible user inputs and outputs, sensor data from the environment is recorded and commands are sent to actuators. ES often need to meet real-time requirements [3, 17]. CPS expand ES with network components for the communication of the subsystems among themselves and over the Internet [14, p. 4]. In CPS, connected ES monitor and control physical processes. This is usually done with control technology, where data from the environment influences calculation processes and vice versa. Control systems make a physical system's output track a desired reference input (e. g. cruise control, thermostat). Feed-forward systems compute a setting for the actuator based on a reference input. Feedback systems also monitor the error between the system output and the reference input and adjust it in response to this error. Control systems should track the reference input even with noise, model errors or disturbances. Thus, there are special metrics to be followed, e. g. stability, performance, disturbance rejection and robustness [18, pp. 246-257].

ES and CPS are the technological basis for many application areas, such as robotics, wearable computing or electronic textiles and disciplines, such as physical computing, interaction design or art that make use of these core technologies in different, often non-technical contexts. Depending on the field of application, different foci are set. Robots, for instance, quite often bring the challenge that their actions are dependent on their environment which is only known at the time of execution, especially when autonomous mobile robots are used in difficult terrain (e. g. space, sea or disaster areas). This makes it impossible to program all suitable action patterns in advance. Robots must therefore capture the environment with sensors, evaluate the data, and initiate appropriate actions depending on the environment variables [12, p. 2]. A typical requirement for such mobile robots is robustness, for instance in high or low temperature areas, in dusty environments or 
under water. Wearables, in contrast, need to be particularly small, light-weight and low in power consumption, which brings challenges to both, hard- and software design.

Although the application areas each specialize their products in different directions, there are many common properties and requirements. For example, in general a distinction is made between continuous time systems, which process signal streams, and discrete systems, which process event- or time-controlled discrete signals [14, p. 43f.]. The design of ES and CPS comes with some technical challenges that occur repeatedly. These include dealing with concurrency in the physical world that needs to be sequentially organized in software, trade-offs between fast and less accurate or slower and more accurate programs, with the heterogeneity of the systems, their interactions and the data they process. Overall, the areas are interrelated and thus understanding certain concepts often requires prior knowledge from neighboring disciplines. The structure of the subject area depicted in Fig. shows the different disciplines in the larger context and represents distinguishing features.

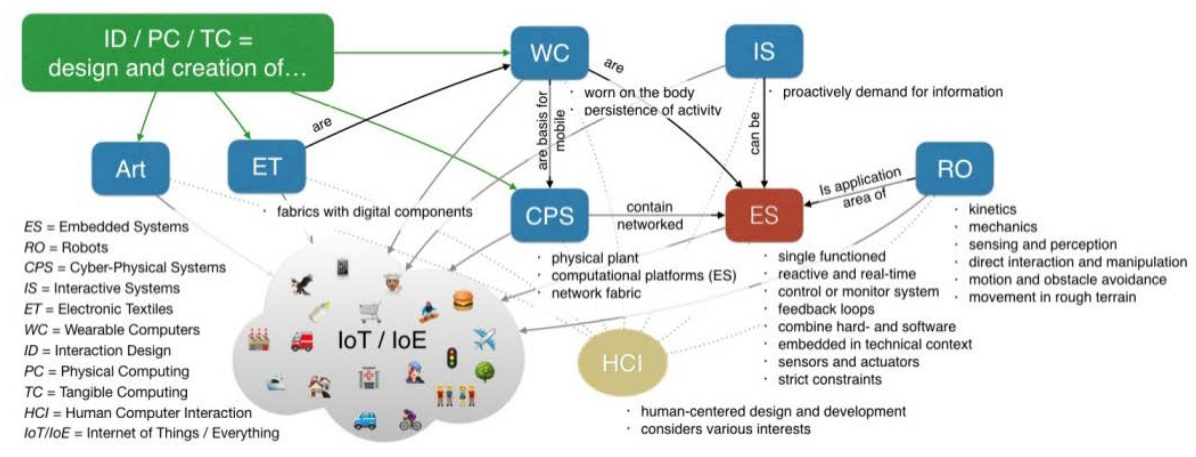

Fig. 1. Overview of different technologies in the Internet of Things

From an educational point-of-view, teaching should be oriented towards the competencies to be achieved, thus this purely content-related structure of the topic is not sufficient for teaching. However, the given overview can provide orientation in order to establish and secure necessary (prior) knowledge and make connections. This way competencies for the analysis, modelling and implementation of ubiquitous computing systems can be developed step by step. As the design and implementation of embedded systems is a great challenge that includes many steps, it is important to provide learners with appropriate contexts, and to investigate phenomena that promote the understanding of abstract content.

\section{Analyzing Social Demands}

The investigation of social demands within a thematic area helps to identify contexts that are relevant for students to cope with requirements that society puts on them in their everyday lives. This way, the significance of computer science for general education is underlined. It is important to realize and consider that social demands 
differ from setting to setting, even between schools in the same district or students of the same learning group under different circumstances [7]. Thus, if the analysis is not performed within a very specific context, it can only reflect general societal demands. Diethelm et al. [7] suggest interviewing stakeholders in education and analyzing constitutions, laws, curricula and standards.

\subsection{Research Goals and Data Gathering}

For analyzing the social demands and to find out how jobs, everyday life and education are effected by embedded and ubiquitous computing systems, we focused on perspectives by stakeholders in this domain that reflect different contexts and help to answer the following questions:

- In which areas are ubiquitous computing systems relevant in our society?

- What are areas in daily life where people encounter such systems?

- In which cases do people need to actively deal with these technologies?

Stakeholders are either active or passive: Active stakeholders are those, who are directly affected by the outcome of this research project, in our case students and teachers in secondary schools. Their perspectives are captured independently with the model of educational reconstruction for computer science education (MER-CSE, [11]). Results from research in this area show that we face some issues in computer science education: embedded, cyber-physical or interactive computing systems are not in students' focus, despite the ubiquity of such devices. Further, none of the students who took part in the study had any prior in-class-experience with activities around those technologies [16]. Also, teachers' prior knowledge is often low and many of them find working with sensors, actuators or microcontrollers intimidating in the beginning [17]. From teacher surveys, we learned that they are concerned about the balance between crafting and tinkering and the actual study of CS but they also see a lot of value in it because they assume that it boosts their students' motivation and creativity.

Passive stakeholders, on the other hand, influence school education from the outside. They form a society's beliefs and norms and thus define social demands that need to be considered. In the study described here, we focused on experts from industry and business, parents, educators and people in general. The aim of this investigation was to get an overview of the stakeholders' interests and demands that they place on CS education. We gained our data from interviews and diverse documents that represent the target groups' interests and conducted a qualitative content analysis of these data, which is based on the methodology of Mayring [15].

Experts from industry and business. We conducted stakeholder interviews with representatives from companies (e. g. Microsoft, Intel, NXP Semiconductors, Adata, Q-Technology) at the "embedded world" conference 2016. Among other questions we investigated their point-of-view on the social impacts of embedded and ubiquitous computing systems and the social demands that are connected to those systems. In short semi-structured interviews (5-15 minutes each), we interrogated the interviewees about general thoughts on ubiquitous computing and more specifically about their ideas for computer science education. The interviews were audio-recorded and then transcribed. In addition to the interviews, we analyzed a policy paper of the 
BITKOM $^{1}$ [3] and passages from a study about basics, applications and consequences of ubiquitous computing [9], which represent the interests of this target group and inform about the current state and future perspectives in the embedded sector.

Parents. To gain parents' expectations on education we analyzed a manifesto from the European Parents Association [8] and two documents from the German Federal Council of Parents: a resolution about self-determined life as a goal of education [5] and a press release on the requirements of digitization on the education system [6]. The Federal Council of Parents is an umbrella organization that represents the parents of about eight million children and adolescents in general and vocational schools in Germany.

Educators. The perspectives of educators are gathered with the analysis of four documents that are relevant internationally and specifically in Germany: In 2013, ACM and Informatics Europe issued a joint report of a working group of experts from academia and industry that reflect many countries' requirements [10]. The German Standing Conference of the Ministers of Education and Cultural Affairs (KMK) has published a strategy paper on education in the digital world [13] that contains many influential ideas and perspectives. Although the KMK has no legislative competence, its decisions are a consensus among the 16 federal states and thus often also lead to implementation in the different curricula. Similarly, the Educational standards published by the German Informatics Society (GI) [1, 2] formally are only recommendations, but find their way into schools in the long term and were hence included in our analysis.

People in General. We included a study of the office for technology assessment at the German Bundestag that represents many of the previously described stakeholders' perspectives [9]. Although this study was published in 2010 already, many aspects are still relevant. Some issues that were mentioned as future visions are reality today. Nevertheless, this study gives a complex overview of topics and especially basics, applications and consequences of ubiquitous computing for all people and diverse areas of everyone's lives. From this document, we also identified the perspectives of laws and press. Laws mirror society and have direct impact on CS education in schools. Press on the one hand reflects, and on the other hand also forms opinions and thus is influential both, as a mirror of society and in shaping it. Given that the press articles in the before-mentioned document were slightly outdated (published in 20052010), we also included more recent articles (published between 2014 and 2017) that were selected based on a keyword search (e. g. sensor, embedded systems, ubiquitous computing, Internet of things) in several German media databases ${ }^{2}$. We focused on German media, as we're primarily creating material for teachers and students in German schools. However, it can be assumed that the results apply to many WesternEuropean countries, possibly with slight differences in the perception concerning ethical questions or when related to country-specific laws.

1 BITKOM: Digital Association of the German Information and Telecommunications Industry

2 ARD Mediathek, including ARD Online and broadcasting channels; Spiegel Online, TAZ, Die Welt, Computer Woche 


\subsection{Data Analysis}

In the analysis, we strove to gain a general overview of topics relevant in our society's discourse, thus we chose a qualitative approach. The overall aim of a qualitative content analysis depends on the context and may include to make statements about the subject matter or, e. g. when analyzing mass media, to find out about their effects on the public [15]. In our case, the aim is to identify requirements our society places on CS education, in particular schools, that come with the increasing pervasiveness of interactive and ubiquitous computing systems. As a first step, we analyzed the interview data. From the analysis goals, we derived the following coding system deductively:

- role of embedded and ubiquitous computing in society today

- role of embedded and ubiquitous computing in society in the future

- relevance of embedded and ubiquitous computing in everyday life

- ethical and social implications associated with ubiquitous computing

- aspects of ubiquitous computing that everyone should know about

- qualifications that applicants to jobs in this domain should have

We identified 142 coding units (sentences and paragraphs of text) in our corpus and expanded the code system inductively based on the data, resulting in 63 codes (paraphrased coding units) that were then summarized into initial categories. These new categories describe the areas where ubiquitous computing is relevant, activities that are closely connected to these technologies, areas with ethical and social implications for and impact on society and general educative goals. These categories were then used for the analysis of the remaining material and refined throughout the process. The resulting category system is based on 271 codes and 1327 coding units and gives an overview of aspects relevant in our society from which social demands can be derived (Table 1).

\subsection{Results and Interpretation}

Our data is captured from different groups of stakeholders and reveals, for instance, that parents focus more on general educative aims, experts from industry and business mention many features of ubiquitous computing systems and their future relevance and press often discusses ethical and social implications of new technologies. For this work, however, we did not consider the single perspectives in detail, but instead combined the data to gain the bigger picture of general social demands relevant for teaching.

The analysis provided an extensive list of contexts, in which ubiquitous computing is relevant in our society, that are often overlapping. Additional categories were created to code activities as active or passive use of systems and to differentiate between today's reality and future visions. It is clearly visible in the data that especially in terms of identification and authentication there is a shift from past to future: while earlier and today, pin protected door locks, fingerprint scanners, RFID chipped cards or even retina scans require action by the user, future scenarios make use of contactless, unobtrusive methods such as face and gait recognition. This raises many questions concerning surveillance, data privacy and security, quite often 
discussed in the media and by people in general, but also reflected in laws and discussions about law changes. Also in other areas, such as health and medicine, passive use of devices is clearly dominant and equally often connected with concerns about possible profiling with personal data, surveillance or safety. The majority of concerns are connected to ethical questions, especially in medicine concerning informational self-determination and privacy, but also in the job sector: many people fear that humans are partially or fully replaced by machines

Table 1. Category system for the analysis of social demands

\begin{tabular}{l|l}
\hline $\begin{array}{l}\text { relevance in } \\
\text { society }\end{array}$ & $\begin{array}{l}\text { environment, smart home, traffic and transportation, health sector, work, } \\
\text { clothing, shopping, economy, authorities, food industry, identification and } \\
\text { authentication, marketing }\end{array}$ \\
\hline activities & $\begin{array}{l}\text { monitoring, prediction of future events, tracking the origin of goods, } \\
\text { surveillance, profiling with personal data, support for ill and elderly, creative } \\
\text { design, regulation and control, preventive action }\end{array}$ \\
\hline implications & $\begin{array}{l}\text { pervasiveness of computing systems, data privacy, data security, system } \\
\text { and impact } \\
\text { dependency, intervening with individual autonomy, informational self- } \\
\text { systems, digital divide }\end{array}$ \\
\hline education & $\begin{array}{l}\text { understand that everything can be programmed and controlled, at- tract all } \\
\text { students alike, interdisciplinarity, involvement of pupils' experiences, basic } \\
\text { principles and fundamental ideas, confidence in dealing with complexity, } \\
\text { superficial goals (reasonability, responsibility, etc.), prepare students for the } \\
\text { future, constructive production of artefacts, focus on competencies and skills }\end{array}$ \\
\hline
\end{tabular}

Despite users becoming more passive in those domains, future scenarios also show that ubiquitous computing systems will become even more pervasive also in everyday situations. No matter whether at home, in grocery stores, in the hospital or at work: everyone will have to deal with these technologies. Although most devices gather their data in the background, they are interactive and involve user actions. Thus, future visions show more active use of technologies than today in these areas.

This trend is also reflected in the general educative aims: according to the data, among other aims, to prepare them for the future and allow them to successfully participate in society, students need to understand that everything can be programmed and controlled. They need confidence in dealing with the complexity of technologies and to constructively produce artifacts instead of only consuming them. Basic principles and fundamental ideas should always be in focus and pupils' experience in everyday life should be considered in lesson planning. 
Table 2. Overview of frequent occurrences in code relations matrix

\begin{tabular}{|c|c|c|c|c|c|c|c|c|c|c|c|}
\hline Code & $\stackrel{\vec{t}}{\underline{d}}$ & $\stackrel{\text { İ }}{\Xi}$ & 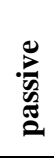 & 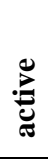 & 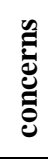 & 离 & $\begin{array}{l}\mathscr{D} \\
\stackrel{2}{2} \\
\text { L }\end{array}$ & 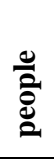 & $\begin{array}{l}\stackrel{\mathscr{Z}}{\text { 巳 }} \\
\text { 光 } \\
\text { L }\end{array}$ & 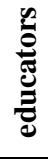 & $\begin{array}{l}\stackrel{\partial}{5} \\
\stackrel{5}{\Xi} \\
. \Xi\end{array}$ \\
\hline concerns & 6 & 16 & 27 & 4 & 0 & 8 & 26 & 39 & 1 & 2 & 3 \\
\hline ethical/social implications & 20 & 13 & 48 & 13 & 82 & 34 & 52 & 35 & 2 & 3 & 14 \\
\hline general education & 5 & 1 & 2 & 11 & 2 & 2 & 0 & 11 & 11 & 65 & 35 \\
\hline work sector & 5 & 3 & 25 & 2 & 30 & 2 & 9 & 62 & 0 & 0 & 14 \\
\hline transportation & 25 & 22 & 24 & 24 & 3 & 0 & 0 & 28 & 0 & 0 & 6 \\
\hline medicine & 6 & 27 & 25 & 2 & 5 & 0 & 1 & 30 & 0 & 0 & 0 \\
\hline health & 25 & 32 & 32 & 4 & 11 & 1 & 7 & 38 & 0 & 0 & 3 \\
\hline identification, authenticat. & 20 & 13 & 16 & 8 & 3 & 0 & 3 & 23 & 0 & 0 & 0 \\
\hline shopping & 4 & 13 & 7 & 8 & 6 & 1 & 1 & 17 & 0 & 0 & 0 \\
\hline smart home & 24 & 13 & 18 & 10 & 3 & 0 & 21 & 21 & 0 & 0 & 4 \\
\hline
\end{tabular}

Table 3. General educative aspects in ubiquitous computing

\begin{tabular}{l|l|l|l|l|l|l}
\hline Code & & & & & \\
\hline understand that things can be programmed, controlled & & & & \\
attract all students alike & & & & & & $\mathrm{X}$ \\
constructive production of artifacts & & & & & $\mathrm{X}$ & $\mathrm{X}$ \\
involvement of pupils' experience & & & & & $\mathrm{X}$ & $\mathrm{X}$ \\
interdisciplinarity & & & & $\mathrm{X}$ & $\mathrm{X}$ & $\mathrm{X}$ \\
basic principles and fundamental ideas & & & & & $\mathrm{X}$ & $\mathrm{X}$ \\
confidence in dealing with complexity & $\mathrm{X}$ & & $\mathrm{X}$ & & $\mathrm{X}$ & $\mathrm{X}$ \\
superficial goals (reasonability, responsibility, etc.) & & & & & $\mathrm{X}$ & $\mathrm{X}$ \\
focus on competencies and skills & & & & & $\mathrm{X}$ & $\mathrm{X}$ \\
participation in future society & & & $\mathrm{X}$ & $\mathrm{X}$ & $\mathrm{X}$ & \\
\hline
\end{tabular}




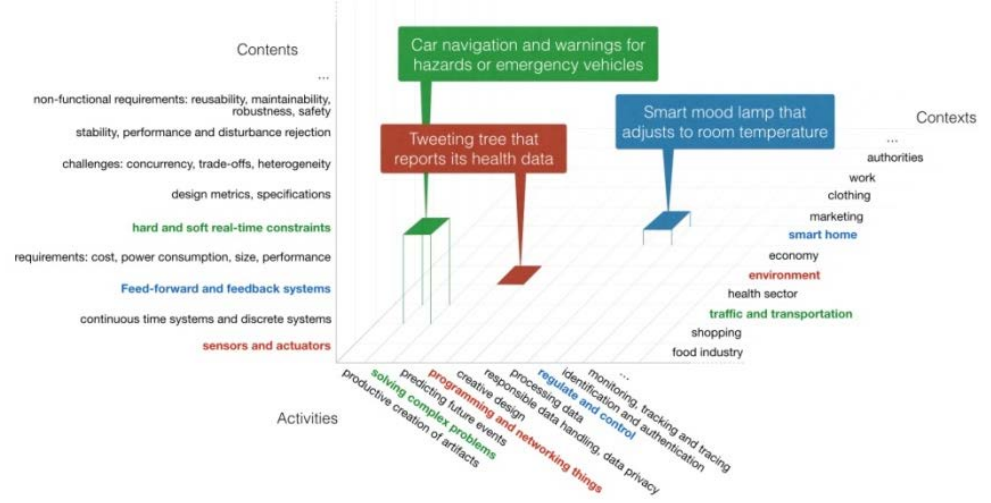

Fig. 2. Matrix of contents, contexts and activities

\section{Conclusion}

Dealing with ubiquitous computing systems, from a technical point of view, requires knowledge, skills and competencies that are less relevant or not present in dealing with transformational systems. Technical terminology has developed significantly over the last decades. Our results show that ES, CPS and similar technologies are relevant in all areas of our life and will become even more pervasive and relevant in the future. Thus, to ensure that everyone can cope with the challenges in our digital world, it is crucial to provide CS education that prepares students to participate in social discourse, to understand media coverage and to make informed judgments. Tomorrow's learning must not neglect the changes in our world and help clarify concerns, raise students' awareness of the risks and opportunities of modern technologies and built competencies so that they are able to customize and control their environment and to deal with new devices, systems and technologies with expertise and without fear. This work provides an empirically developed basis of contexts and activities from which phenomena and specific teaching scenarios can be developed that support modern and general educative computer science education.

\section{References}

1. Arbeitskreis Bildungsstandards der Gesellschaft für Informatik e.V.: Grundsätze und Standards für die Informatik in der Schule [Principles and standards for computer science in school], LOG IN 28 (150/151), supplement (2008).

2. Arbeitskreis Bildungsstandards SII der Gesellschaft für Informatik e.V.: Bildungsstandards Informatik für die Sekundarstufe II [Educational standards for secondary education] LOG IN 36 (183/184), supplement (2016).

3. BITKOM: Eingebettete Systeme-Ein strategisches Wachstumsfeld für Deutschland [Embedded Systems-A stratgic growth area for Germany], http://www.bitkom.org/files/documents/EingebetteteSysteme_web.pdf, last accessed: 2017/07/26. 
4. Bojanova, I., Hurlburt, G., Voas, J.: Imagineering an Internet of Anything. Computer 47(6), pp. 72-77 (2014).

5. Bundeselternrat: Selbstbestimmtes Leben als Ziel von Bildung-Was müssen unsere Kinder heute lernen? [Self-determined life as a goal of education-What do our children have to learn today?], http://www.bundeselternrat.de/files/Dokumente/Resolutionen/2016/Bundeselternrat_Reso _Selbstbestimmtes_Leben_als_Ziel_von_Bildung20160424.pdf, last accessed: 2017/07/26.

6. Bundeselternrat: Digitalisierung / Individualisierung. [Digitization / Individualization.], https://bildungsklick.de/schule/meldung/digitalisierung-individualisierung/, last accessed: 2017/07/26.

7. Diethelm, I., Hubwieser, P., Klaus, R.: Students, teachers and phenomena: Educational reconstruction for computer science education. In: Laakso, M.-J., McCartney, R. (eds.) Proceedings of Koli Calling '12, pp. 164-173. ACM, New York, NY, USA (2012).

8. European Parents' Association: Manifesto 2015, http://euparents.eu/manifesto-2015/, last accessed: 2017/07/26.

9. Friedewald, M., Raabe, O., Georgieff, P., Koch, D.J.: Ubiquitäres Computing. [Ubiquitous Computing.] Nomos Verlag, Berlin, Germany (2010).

10. Informatics Europe \& ACM Europe Working Group on Informatics Education: Informatics Education: Europe Cannot Afford to Miss the Boat. Tech. rep. (2013).

11. Grillenberger, A., Przybylla, M., Romeike, R.: Bringing CS Innovations to the Classroom Using the Model of Educational Reconstruction. In: Proceedings of ISSEP 2016, pp. 3139. Münster, Germany (2016).

12. Hertzberg, J., Lingemann, K., Nüchter, A.: Mobile Roboter [Mobile Robots], vol. 7. Springer-Verlag, Berlin Heidelberg (2012).

13. Kultusministerkonferenz: Bildung in der digitalen Welt [Education in the digital world], KMK, Berlin, Germany (2016).

14. Lee, E.A., Seshia, S.A.: Introduction to Embedded Systems - A Cyber-Physical Systems Approach, Second Edition, MIT Press (2017).

15. Mayring, P.: Qualitative Content Analysis. Theoretical Foundation, Basic Procedures and Software Solution. Klagenfurt, Austria (2014). URN: http://nbnresolving.de/urn:nbn:de:0168-ssoar-395173, last accessed: 2017/07/26.

16. Przybylla, M., Romeike, R.: Overcoming Issues with Students' Perceptions of Informatics in Everyday Life and Education with Physical Computing-Suggestions for the Enrichment of Computer Science Classes. In: Gülbahar, Y., Karatas, E., Müge, A. (eds.) Proceedings of ISSEP 2014, pp. 9-20. Ankara University Press, Ankara, Turkey (2014).

17. Przybylla, M., Romeike, R.: Teaching Computer Science Teachers-A Constructionist Approach to Professional Development on Physical Computing. In: Sipitakiat, A., Tutiyaphuengprasert, N. (eds.) Proceedings of Constructionism 2016, pp. 265-274. Suksapattana Foundation, Bangkok, Thailand (2016).

18. Vahid, F., Givargis, T. D.: Embedded System Design: A Unified Hardware/Software Introduction. Wiley, New York, NY, USA (2002).

19. Weiser, M.: Some Computer Science Issues in Ubiquitous Computing. Communications of the ACM 36(7), 75-84, New York, NY, USA (1993). 